\title{
The Design of Akhmat Tower
}

\author{
Sara Beardsley ${ }^{1 *}$, Alejandro Stochetti ${ }^{1}$, and Marc Cerone ${ }^{1}$ \\ ${ }^{1}$ Adrian Smith + Gordon Gill Architecture, 111 West Monroe, Suite 2300, Chicago, Illinois 60603, \\ USA
}

\begin{abstract}
Akhmat Tower is a $435 \mathrm{~m}$ supertall building designed by Adrian Smith + Gordon Gill Architecture. It is currently under construction in the city of Grozny, in the Chechen Republic, in the North Caucasus region of Russia. The design of the tower was done during a collaborative process by a multi-disciplinary architectural and engineering team, based primarily in the United States and Russia. During this process, the designers considered many factors including, most primarily, the cultural and historical context, the structural requirements given the high seismicity of the region, and the client's programmatic needs. The resulting crystalline-shaped tower is both an aesthetic statement and a performative architectural solution which will be a new landmark for Chechnya. "The Design of Akhmat Tower" describes in detail the design process including structural considerations, exterior wall design, building program, interior design, the tuned mass damper, and the use of building information modeling.
\end{abstract}

\section{Introduction}

In 2014, Adrian Smith + Gordon Gill Architecture (AS $+\mathrm{GG})$ was commissioned to design a signature tower adjacent to the Suzha river in Grozny, Chechnya - a Republic of Russia located in the north Caucasus region near the Caspian Sea. This tower is to be a new icon specifically for the region - and is named after the first President of Chechen Republic, Akhmat Haji Kadyrov [1]. The design was done by a team of over one hundred people, based primarily in the United States and Russia, and utilized expertise from architects and engineers with vast experience in super-tall building design. The $435 \mathrm{~m}$ tower, currently under construction, is planned to be completed in 2020 and at that time will become the tallest building in Chechnya and the second tallest building in Russia [2]. The only tower that will exceed its height is the Lakta Tower in St. Petersburg, which also under construction [3]. This case study, «The Design of Akhmat Tower», documents the design process for Akhmat Tower, the resulting design solution and the many factors that contributed to its development.

*Corresponding author: sarabeardsley@smithgill.com 


\section{Process \& Methodology}

\subsection{Design Team}

Adrian Smith + Gordon Gill Architecture (AS+GG), the design architect, is a firm which was established in 2006 and is dedicated to high performance, energy efficient and sustainable architecture on an international scale [7]. The firm's portfolio features several super-tall buildings including as the $1000 \mathrm{~m}$ Jeddah Tower, which is to be the world's tallest building when complete, and the $600 \mathrm{~m}$ Wuhan Greenland Center. Adrian Smith, one of the design partners, has over 40 years of experience specifically working on super-tall projects, including the Burj Khalifa. He is known for 'global environmental contextualism' [4] and follows the principle that each design should be a specific response to its site, country of origin, and environment.

Thornton Tomasetti, the structural engineering firm responsible for Akhmat Tower, is also world-renowned in the design of super-tall buildings and for their experience in designing tall buildings high-seismic areas, such as Taipei 101, completed in 2004 [5]. The design team also included the civil engineers Langan, Inc.; wind engineers Rowan Williams Davies and Irvin, Inc (RWDI); vertical transportation consultants Fortune Shepler Saling; and the architect of record, Gorproject, based in Moscow, Russia.

\subsection{Design Process}

The design team worked closely with the client, Smart Building, Inc. through a series of workshops during all phases of the project. During the early concept design phase, Adrian Smith + Gordon Gill Architecture proposed three independent massing concepts. The client selected a tapering pyramidal shaped tower as the basic architectural massing form, and from that point, the complex geometry of the tower base and tower crown was further studied and developed. The design was optimized with input from both the structural engineers and the wind tunnel test results, and in response to the needs of the interior programmatic elements of the building. It was an iterative process which took place over a period of over 1 year. The development of the architecture was led by the design team in Chicago with input from the architect of record, Gorproject, especially concerning compliance with local codes and Russian standards. The Thornton Tomasetti team included engineers based in Russia. This close collaboration between local and international architects and engineers is very beneficial when performing a project of this scale.

\subsection{Design Criteria}

The design of Akhmat Tower required a strong historical and cultural reference. The client requested that he tower be influenced by the traditional Nakh watchtowers which are commonly found in traditional Chechen medieval architecture (see Fig. 1). This medieval watchtower is the most recognizable symbol of historical Chechen architecture and represented advanced building techniques for their time. The traditional four-sided watchtowers were typically square or nearly square in plan, always tapering, with a prominent series of window openings on the south façade. The construction of these towers reached its height from the $13^{\text {th }}$ to the $17^{\text {th }}$ centuries [6], as dwellings and for military defense. The defensive towers were often beacons of communication from one village to another, as they were typically found on a hill or mountain top. While the form of the watchtower was square in plan, the pinnacle of the was either flat, or a slightly pyramidal shape with a capstone. The client's desire for a 
strong historical reference as a design criteria for the project was a challenge and an opportunity for the design team, which had the task of creating a contemporary building that reflected the technology of the future, but also had reverence to the past.
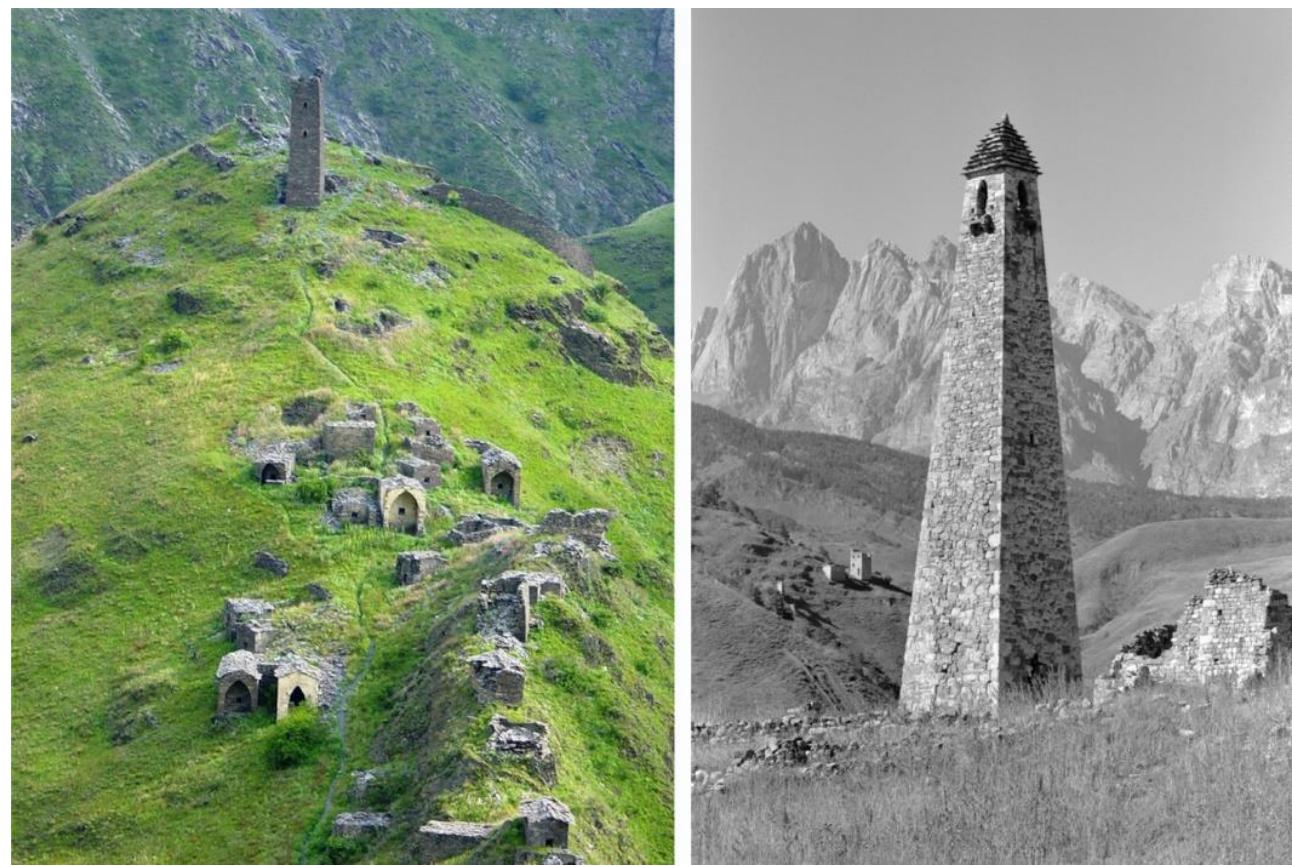

Fig. 1. (Left) Tsoi-Pheda Tower, Chechnya and (Right) Guard Tower in Ingushetiya.

The client's program for the building, which is mixed-use consisting of office, hotel, residential, observation, restaurant and retail uses - required a strict separation between functions in order for the building to operate smoothly and accommodate the arrival sequence for all of the building users and visitors. These programmatic needs, consideration for security and access, and the spatial needs of the hotel amenities heavily influenced the design of the building base, which incorporates the mixed-use functions of the building in multiple levels. The topography of the landscape design was used to reinforce the separation of building uses. The development of the building core and the placement of the technical floors was carefully coordinated to facilitate the most optimal layouts, lease spans, and elevator zoning. Building performance and energy use criteria were also of significant consideration.

Structural requirements strongly influenced the architectural design. The design process required very close coordination between the architectural and structural design needs, due primarily to the high seismic zone where the project is located, and its height of over $400 \mathrm{~m}$. The architects had to create a design that both worked from a planning point of view and was cost effective and efficient from a structural point of view. The design team extensively used Building Information Modeling (BIM) to document the design and share information between members of the design team. The complexity of the exterior wall design pushed the envelope in terms of three-dimensional modeling and required the use of innovative software tools in order to create the production drawings. 


\section{The Design of Akhmat Tower}

\subsection{Design Concept}

In response to the historical reference of the medieval watchtower, $\mathrm{AS}+\mathrm{GG}$ 's design vision for the Akhmat Tower shares a strong geometric relationship in its architectural proportion, the use of a four-sided pyramidal shape and monumental top. The tower base design incorporates flared geometry and earth berms - a reference to the traditional watchtowers which were always on a hilltop or mountain (see Fig. 2). The division of the tower form into a distinctive top, middle and bottom zone parallels the watchtower design which also had the same three parts. The size of the pinnacle of Akhmat Tower utilizes a similar proportion to the top of the traditional watchtower. During the design, the prominence and size of the pinnacle was carefully considered in order to reinforce the relationship to the traditional tower. The crystalline shape of the pinnacle has a specific indented center to its geometry whose location relates to the location of the window opening that is typically present in Nakh watchtowers. Four sloping walls taper to reach the observation and museum floors at the top of the building, taking advantage of the pinnacle's volume, which features distant views of the presidential palace, the Akhmad Kadryov Mosque, and the distant mountains. Akhmat Tower's pinnacle is used as an observation space where one can overlook the city of Grozny, just as the medieval watchtowers were used to survey distant lands.
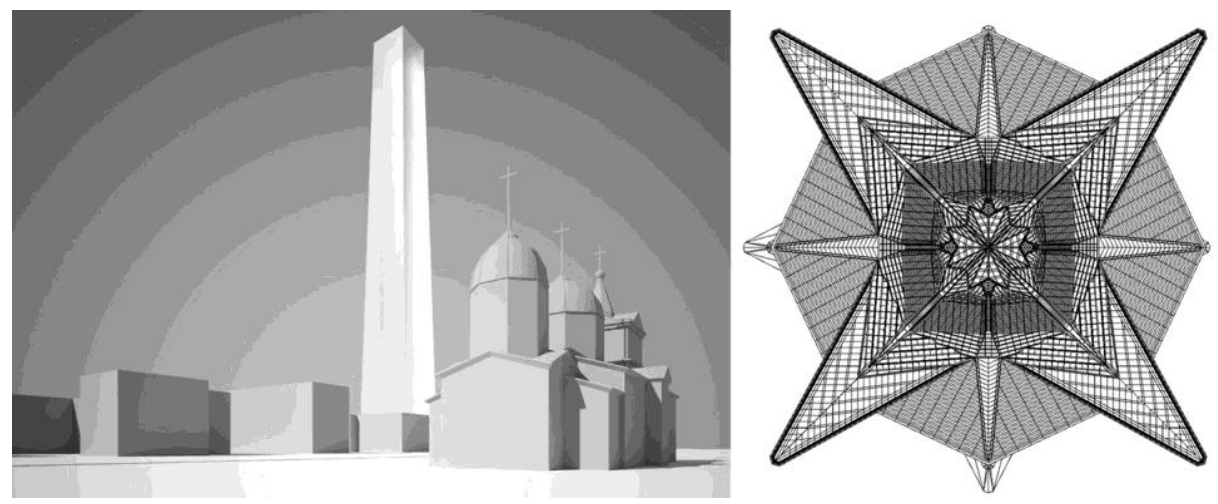

Fig. 2. (Left) Early Conceptual Massing View from Mosque, (C) AS+GG 2017 and (Right) Geometry Plan of Akhmat Tower, (c) AS+GG 2017

The use of the square plan, and the symbolism of the geometry formed by two intersecting squares, is very important in terms of the historical reference to Chechen architecture, which used square plans in nearly all of the historical buildings [6]. The shape formed by two intersecting squares, one rotated at 45 degrees to the other, is also seen in traditional Islamic patterns. The idea of the square, diamond, or rotated square geometry is repeated throughout different elements of the tower and in the exterior wall panels.

Similar to the hilltop setting of Nakh Towers, the landscape design of Akhmat Tower situates the building and its multi-level lobbies atop a landscaped hill. Drop-off zones for the different uses of the tower are reached through roads at various levels, accessing the different sides of the tower with elegant earth berms negotiating the elevational differences. The freeflowing berms contrast with the sharp geometry of the tower design itself, in the same way the historical towers were juxtaposed against the green hills of the North Caucasus region. Native plantings and trees are used throughout the design. Water features welcome visitors in the drop-off areas of the tower, recalling the rivers found in the region. 


\subsection{Tower Program}

Akhmat Tower has an approximate gross area of 250,000 square meters, containing office, hotel, residential, observation and retail spaces (see Fig. 3). Because the building tapers, the program is organized in order to utilize ideal lease spans in each zone. The building has one basement level, containing parking and mechanical spaces. The main lobbies exist on two levels with the office lobby located at level 1 and the hotel lobby located at level 3. Both lobbies have visual access to the 8 -story atrium above. Each program type has separate dropoffs on various sides of the building. The observation drop-off, at the north side of level 1 , is adjacent to the public retail entry and retail mall connection. The hotel ballrooms, wedding suite, grand lobby, and restaurants are all located at the upper level 3 lobby.

Within the tower, the office program occupies the lower 10 levels of the building, followed by 7 hotel guest room floors, and 11 levels of serviced apartments. The upper 49 levels of the tower are residential units culminating in 2 levels of penthouse units at the top. The pinnacle features a signature restaurant, an observatory, and exhibit space.

The elevator system for Akhmat Tower is divided into zones by program. All tower functions are served with a local elevator system which takes passengers directly from the lobby to the floor of occupancy. While express elevator shuttles and transfer floors are often seen in a building of this size, it is most efficient, luxurious, and convenient to use a system that does not require elevator transfers. Therefore, Akhmat Tower was designed with direct elevator service from the lobby to the occupied floors. Dedicated parking, public, hotel amenity, and retail elevators serve the base of the building, ensuring security and privacy for the main tower elevators.
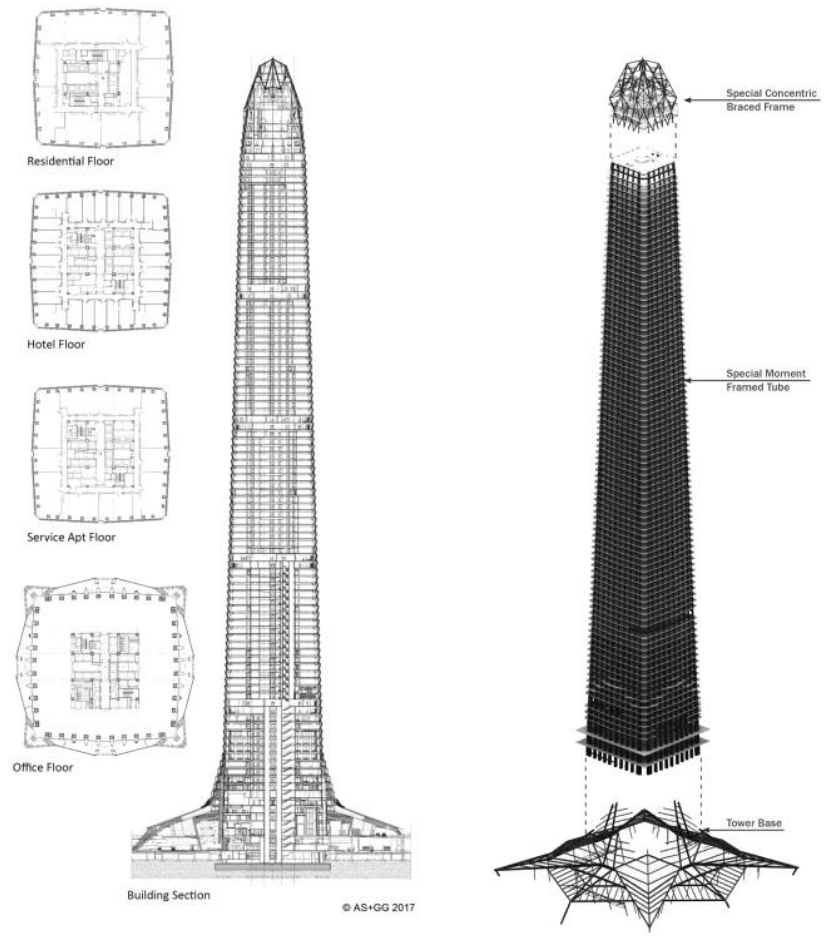

Fig. 3. (Left) Plans and Section of Akhmat Tower, (CAS+GG 2017 and (Right) Structural Design Diagram, (C) Thornton Tomasettti, 2017 


\subsection{Integration of Structural Design and Architecture}

The seismicity of Grozny is one of the highest in the world, exceeding San Francisco by fifty percent and the seismic criteria used in Taipei 101. Most new supertall buildings utilize either completely concrete structures, with shear-walls on every floor, or composite concrete and steel structures, which allow the buildings to have very few large columns and rely on outrigger trusses located at the technical floors. Neither of these solutions was suitable or efficient given the seismic loads in Grozny.

A building which behaves well in a highly seismic area needs to be sufficiently ductile, and should have a uniformity to the structural design in order to minimize any areas where loads could be concentrated during an earthquake event. Therefore a customized, evolved version of the steel 'perimeter tube' system was chosen for Akhmat Tower. The perimeter tube system, which was utilized in the Willis Tower in Chicago and the original World Trade Towers in New York, requires a closely spaced set of columns at the perimeter of the building. These perimeter columns and coupling beams will create the world's tallest «special moment frame» seismic resisting system once realized [5] (see Fig. 3).

Akhmat Tower's perimeter columns, spaced at $4.5 \mathrm{~m}$ on center, are sufficiently small as to minimize their impact on the usable interior space. The steel perimeter columns are typically less than $1 \mathrm{~m}$ in size, which is an advantage over a mega column system, which commonly has columns of two meters or more. The column layout of Akhmat Tower is designed so that there is no corner column, allowing the corners to be chamfered and include windows that offer views out diagonally. The use of a special moment frame structure meant that the technical floors could be designed without large outrigger trusses, making them faster and more simple to construct, and easing the layout in terms of fitting the mechanical equipment on those floors.

\subsection{Performative Massing and Exterior Envelope Design}

The design of the final shape of Akhmat Tower was influenced by wind performance. From the conceptual phase of the project, a square-shaped building was desired. However, it was also noted early on by the design team that square-shaped plan with sharp square corners was not ideal for wind performance. Thus, as design refinements were done, consideration was given to optimizing the form in a way that improved its behavior. This optimization reduced wind loads on the building, making the structural members more efficient, saving significant tonnage and cost in steel.

The earliest conceptual design included a completely flat top pinnacle and a completely square plan, yielded a wind-load response that was estimated to be up to $15 \%$ greater than the more refined final design. The final design incorporated two-meter chamfered corners and a forty-fiver meter tall, sculpted, crystalline top. The shaping of the base of the building also showed a measurable benefit. It was found through wind test data that pedestrian wind comfort in the spring, summer and fall was in an acceptable range with very little mitigation. This performance is attributed to the shape of the flared base and canopies, which shield pedestrians from wind coming down the face of the tower.

In the design of Akhmat's building envelope, the stone wall patterns of traditional architecture of Chechnya are reinterpreted and materialized in a three-dimensional developed glass, aluminum and stainless-steel wall. The exterior wall has a three-dimensional shape that protrudes at each floor and slopes back toward the main volume, thereby reducing glare and solar gain to the façade. The shingled wall has a curved corner, which forms a stainless steel accent piece that catches the sunlight. Operable mullions are fully integrated with the wall 
design, enabling the façade to have a strong consistency. Specifically designed picture windows at the corners offer enhanced views while also improving the tower's response to wind loads.

The exterior wall of Akhmat Tower is a next-generation development of the architects' Federation of Korean Industries (FKI) Headquarters exterior wall in Seoul, Korea, which was completed in 2014 and was tilted downward 10 degrees (see Fig. 4). During the design of the FKI project, solar analysis showed that the greater the wall's downward tilt, the less glare and solar heat gain would be realized versus a flat curtainwall. The typical Akhmat wall has a 14-degree downward tilt. The incorporation of the 80-millimeter-tall operable mullions was driven by a programmatic need for natural ventilation up to nearly 400 meters in height for the residential units. On windy days, especially on the upper floors of supertall buildings, traditional operable windows tend to be used less frequently by occupants due to powerful wind gusts flowing through the occupied floors, and difficulty opening or closing the windows. The operable mullion provides controlled natural ventilation, utilizing a button to open and close the device. This encourages natural ventilation to be used during more times of the year and alleviates some of the perceived safety concerns associated with open windows at such heights.
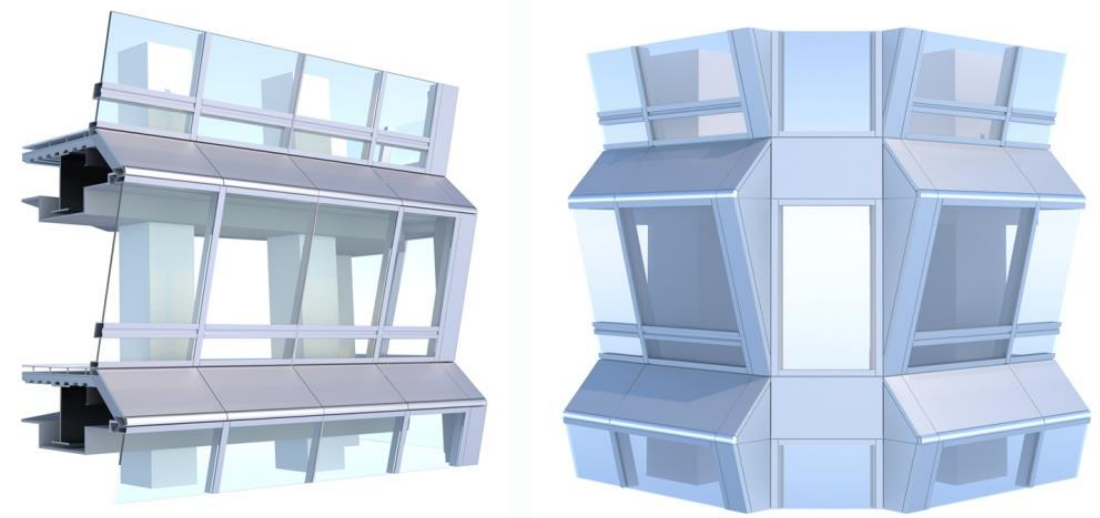

Fig. 4. (Left) Typical Exterior Wall, (C) AS+GG 2017 and (Right) Corner Exterior Wall, (CAS + GG 2017

The texture and tilt of the exterior wall is continuous from the bottom of the tower pinnacle to the canopies at Level 2. As the wall reaches the bottom of the tower, it flares dramatically at the base, forming the eight-story atria that frame each lobby of the building. The atria create a double-skinned wall - a monumental volumetric space that can be viewed from the lobbies below and from the lower office floors. The atrium base extends out to form glass wings that act as sky-lit spaces, which frame the entries to the lobbies. Triangular, shingled canopies extend dramatically over each drop-off. Operable louvers within the atrium exterior wall system are linked to the smoke evacuation system, using the tapering shape of the atrium to help draw air upward, and out.

The crystalline geometry of the tower pinnacle is a special feature in the exterior wall design. The many facets catch the light as it hits the building at different angles. The volumetric spaces inside the pinnacle include the two-story tuned mass damper, which was designed as part of the public observation area, as well as a multi-story volume at the top that forms the museum and restaurant. The steel tube structure is minimally clad, in order to expose the complex geometry; fritted glass is used to control glare. The building's maintenance system for cleaning the peak is strategically integrated into the top of the tower, above the core, using operable swing panels that open when the unit is deployed. 


\section{Interior Design and Planning}

The form of the tower base informed the unique spatial opportunities of the interior design of the office, apartment, and hotel lobbies and became a primary influencer to the design. The office and apartment drop-off elevation is situated below the hotel lobby on level 1 , allowing for a continuous space for the hotel program above. Taking advantage of the soaring and sculptural spaces created by the tower base form, the office and apartment lobbies are outside of the tower columns, further separating the hotel by walls of stone at the office and wood at the apartment lobby. The spaces are naturally lit, the angular feature walls as a backdrop. The structure creates a sense of a screen to the office and apartment's inner lobbies, respectively, which naturally form more intimate spaces. Materials become warmer and more tactile as building users progress to the lift lobbies in the core.

The hotel lobby program benefits from the ability to have an almost totally circular flow around the core of the building on level 3 (see Fig. 5). The reception lobby is an impressive 50 meter tall winter garden with light dappling in from the tower base's roof skylights. Exaggerated column enclosures allow passive air to circulate by a series of integrated grilles and ducts that move the air though natural convection. A series of interior trees create a canopy over the seating and social areas of the lobby, bringing these areas down to a more human scale, enhancing guest comfort and functionality of the grand space.
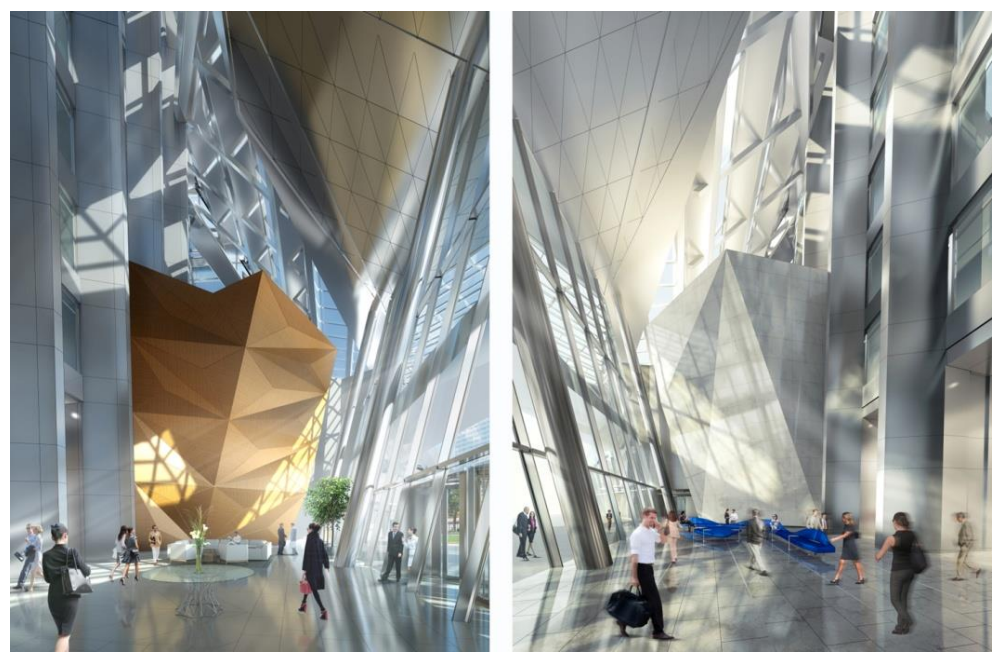

Fig. 5. (Left) Office Lobby Interior, (C) AS+GG 2017 and (Right) Hotel Lobby Interior, (CAS+GG 2017

Restaurants are situated in two of the four arms of the public floor of the hotel, while the ballroom pre-function and bridal support spaces are housed in the other two arms. The tower base form and structure create a virtually column-free space for a 700 square meter ballroom that has a column free and sun lit pre-function area.

Additional personal and attentive functions of the guest experience are tucked away on the $21^{\text {st }}$ floor of the 165-key hotel. Spaces such as guest check in, guest lobby and lounge, cocktail lounge and all-day dining are arranged in a club-like atmosphere, providing a sense of exclusivity and privacy for guests. Spa functions on level 4 are accessible to the hotel as well as to the apartments and serviced apartments.

The interior design of the building takes much inspiration from a local traditional dance called The Lezginka, which means "the dance of the eagle and the swan." This national dance, shared by people in the Caucasus region, is performed during special occasions and weddings. In it, a male dancer becomes an eagle with sharp, angular motions and a woman 
dancer becomes a swan with soft, fluid circular movements. This memorizing juxtaposition of totems motivates the dialogue of the tower's interior design forms and furnishings. The frenzied dance with its sharp, strong, and angular form, further enhances the narrative of the architectural design.

\section{Tuned Mass Damper}

Akhmat Tower requires a tuned mass damper as part of its design. The damper is required not for reasons of structural strength, but instead to retain occupant comfort. A steel building is designed to have more movement than a concrete structure, which is one of the reasons it performs so well in an earthquake. The damping is required in order to make sure the upper floors of the building are very comfortable for occupants as the building moves. This is especially true given that the upper floors are residential, where comfort perception limits are the most strict.

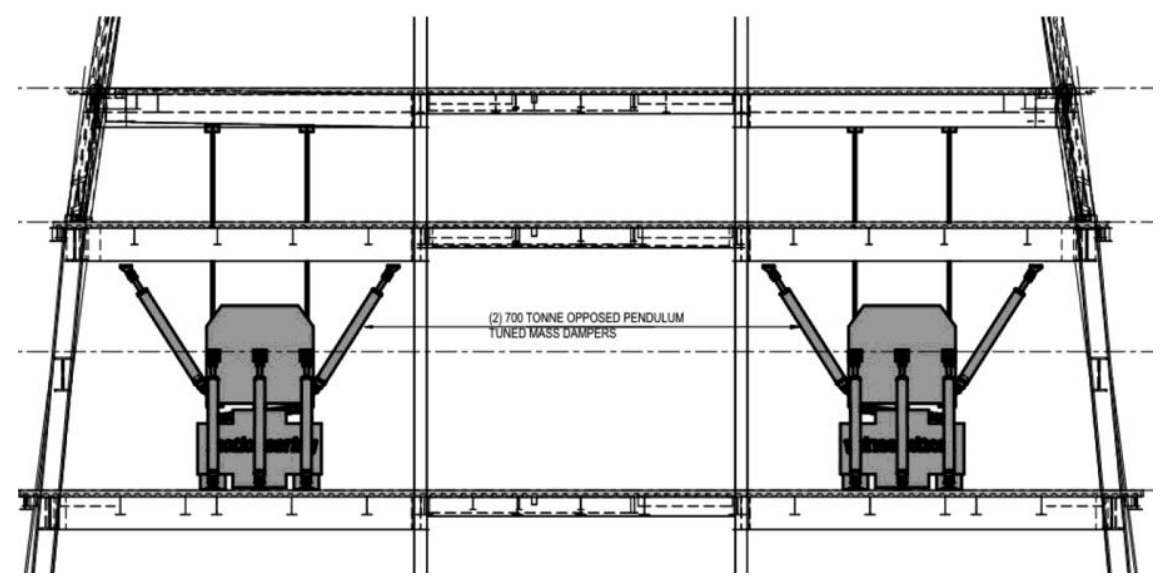

Fig. 6. Tuned Mass Damper Section Diagram, (C) RWDI 2017

The two tuned-mass dampers (TMDs) are located on Level 96 - above the residential floors and directly below the observation floor (see Fig. 6). Because of the tapering shape of the tower, floors become quite small near the top of the building and finding enough space was a significant challenge. The layout of the core required that the express elevators and fire-fighting elevators be located at the center of the building, necessitating a non-centralized location for the damper in plan. It was decided early in design that the damper would be split up into two locations on each side of the core. Although two dampers are not as spaceefficient as a single damper overall, it was found that the two dampers did satisfy the required performance and that it was a feasible approach. The layout of the two dampers also leaves ample space for the building maintenance machines to co-exist on the double height technical floor.

In addition to the challenges of fitting the dampers in plan, the height requirement of the damper in order to achieve the necessary swing of the cables presented another challenge. The solution was to allow the cables to extend up through floor 98 - into the observation deck. Glass handrails will be built around the cables and a glass floor will be installed so that visitors to the observation deck can view tuned mass damper. In this way, the tuned mass damper will be used as an architectural feature, and educational exhibit, to show building visitors how dampers are used in super-tall buildings. 


\section{Building Information Modeling (BIM)}

Adrian Smith + Gordon Gill Architecture uses building information modeling extensively in its production of drawings. While the early design process is done with Rhino, a three-dimensional modeling design program, the working drawings are done in Autodesk Revit. The issuance of drawings for Akhmat Tower was done entirely from Revit. The model took the team over a year to develop from start to finish. The use of Revit was multi-disciplinary, including the structural and mechanical engineers, interiors team, lighting design and landscape. The various models were separated based on sub-teams within the project; the largest models being the «core» and «exterior wall». As the design evolved, translation between Rhino and Revit was required on a regular basis.

The creation of the accordion-shaped exterior wall in Revit was a complex process, which was done using Rhino, various plug-ins, and translated to Revit using adaptive components. The typical exterior wall family was a panel that contained twelve main geometry points. The most complex part of the exterior wall modeling process was to build the tapering corners and the trapezoidal panels that flared and tapered as they connected the main exterior wall to the atrium. By the end of the project, the entire exterior wall was usable directly from Revit without use of masking or placeholder geometry, so that any part of the model could be cut accurately in plan and in section. One advantage of the design was the symmetry - as it was only necessary to build one eighth of the main exterior wall, which could then be mirrored 8 times.

\section{Discussion: Why Supertall?}

Akhmat Tower is an example of a supertall building that integrates the latest technology, and will become a new landmark for the region of Chechnya. It will attract visitors to its museum and restaurants, and luxuriously accommodate its hotel guests, office tenants and residents. It is important for the designers of super-tall buildings to consider the overall impact of tall buildings on the environment, and examine the question: Why build a super-tall building? Adrian Smith + Gordon Gill Architecture has done extensive research into the energy impact of tall buildings and analysis of how these buildings fit into the urban fabric of our cities. While super-tall buildings are energy intensive, they can be designed with excellent energy performance, and energy standards are becoming more strict as technology advances.

AS+GG is currently performing research called «The Density Study» whereby different buildings were analyzed in terms of their impact to carbon emissions. Nine typologies of residential buildings, from a single family home, to low-rise, to mid-rise, to supertall, were modeled to find out which is the most ideal density in terms of creating the lowest environmental impact (see Fig. 7). The findings showed that the density with the greatest negative effect on the environment is a single-family home, but the second most impactful was the supertall, which for the purposes of the study, is categorized as a building from $300 \mathrm{~m}$ to $600 \mathrm{~m}$ in height. The extra energy used in a supertall building is primarily due to the space and energy requirements for the elevator system, and to move mechanical services, electricity and water throughout the building. The initial study found that the most efficient or 'ideal' urban density [in terms of carbon emissions] would be a 3-4 story walk up apartment building, which has a very low energy load from its building systems and low use of land area. Why then, if super-tall buildings are an energy intensive typology, should they continue to be built? The answer to this question is complex and has to do with deeper principles of urban planning and the way that we live in the $21^{\text {st }}$ century. 


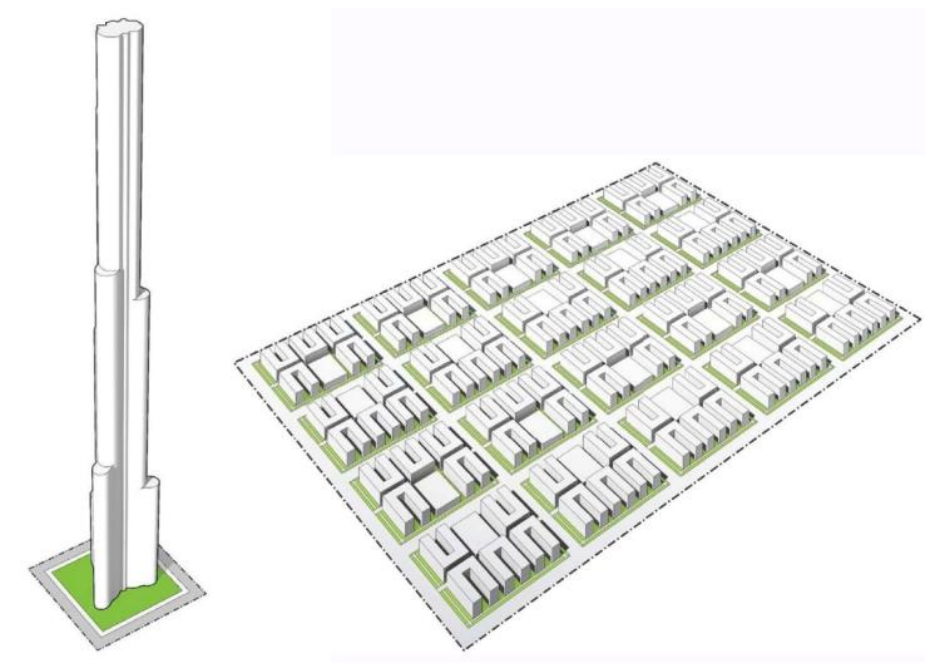

Fig. 7. (Left) Supertall Prototype Diagram, (C) AS+GG 2017 and (Right) Courtyard. Prototype Diagram (illustrating the number of courtyard buildings equivalent to a supertall prototype), C AS $+\mathrm{GG}$ 2017.

Supertall buildings were first invented in the $20^{\text {th }}$ century as the technologies that were necessary to build them were developed. These structures became important to cities as our modern landmarks, and symbols of prosperity and identity. They are also important as catalysts for development of urban centers. A supertall building is most often located at the center of a successful business district of a city, where land value is the greatest. Typically the buildings directly around the super-tall become commercial centers for those cities. Supertall buildings also attract culture, tourism and public amenities at their base and the areas direction around them, often incorporating major transit hubs. Therefore the supertall building cannot be looked at in isolation - it must be considered for the important part it plays in the urban environment and for its role as an icon or symbol for the city where it is located and as a catalyst for the city around it.

Even though a low-rise building may be the most energy efficient density, it is important for major cities to have a mix of densities and a very dense urban core, in order for those cities to prosper. In the $21^{\text {st }}$ century, more people are living in cities than ever before. Increasing density is advantageous in the future, because it will minimize sprawl as the world population grows. Supertall buildings have become an important part of our society and are part of the growth of urban density that will continue over the next century and beyond.

\section{Conclusion}

Super-tall buildings are important landmarks that have special meaning to the cities where they are built. Akhmat Tower is a building that will honor the past and represent the culture of Chechnya, while also becoming a symbol of hope and future prosperity (see Fig. 8). Akhmat Tower is a unique building which responds to the environment where it is located, the requirements of the client's program and structural challenges. The crystalline shape of the pinnacle, the monumental tower, and the soft curves of the site design give the tower its unique identity and create architecturally significant public spaces which will be enjoyed by the occupants as a new center for the city of Grozny. 


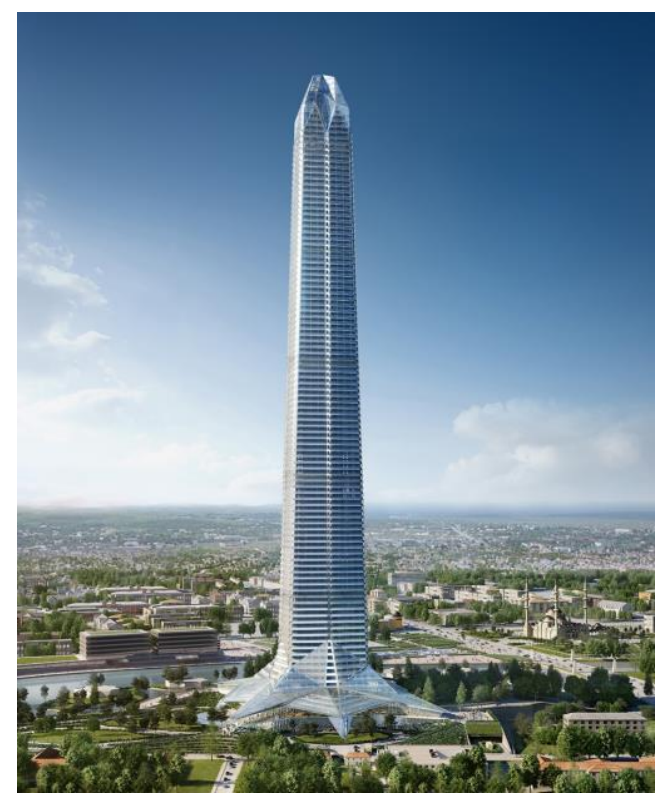

Fig. 8. Overall View, Akhmat Tower, (c) AS+GG 2017.

\section{Acknowledgements}

We would like to acknowledge the entire Akhmat Tower AS+GG Design team: in particular, Adrian Smith; Gordon Gill; Robert Forest; Sae Hwang Oh; Alejandro Stochetti (Design Director); Myongki Seong; Nathan Diestelkamp; Sung Hak Ko; James Struthers; Yuchen Liu; Marc Cerone.

Additionally, the AS+GG Density Study research team, including Chris Drew, Director of Sustainability, and Natalia Quintanilla, energy modeler.

The Akhmat Tower consulting team: Thornton Tomasetti Engineers; Langan Engineering \& Environmental Services; Positivenergy Practice MEP engineers; FS2 Vertical Transportation Consultants; RWDI Wind Engineers; Lerch Bates Façade Access; Garth A Wemmer Landscape Architecture, LLC; Forcade Associates, Graphics; Gorproject, Architect of Record.

\section{References}

1. www.smbuild.ru (last accessed 2017/08/26)

2. www.skyscrapercenter.com (last accessed 2017/08/26)

3. www.lakhta.center/en (last accessed 2017/08/26)

4. Smith, Adrian. The Architecture of Adrian Smith, SOM: Towards a Sustainable Future, (Images Publishing Group, 2007)

5. www.thorntontomasetti.com (last accessed 2017/08/26)

6. http://lechailyasov-eng.com «Medieval Chechen Architecture» (last accessed 2017/08/26)

7. http://smithgill.com/news/csr_2013/ (last accessed 2017/08/26) 